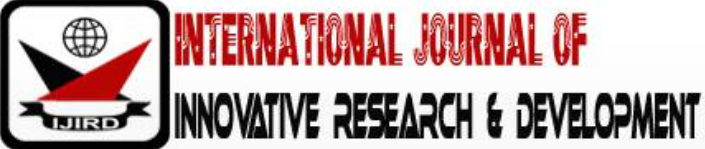

ISSN 2278 - 0211 (Online)

\section{Inhibitory Effect of Moringa Oleifera on Gastric Acid Secretion}

Dr. Augustine Adugba
Lecturer, Department of Physiology, College of Health Sciences,
Benue State University, Makurdi, Nigeria
Christian Onahinon
Researcher, Department of Physiology, College of Health Sciences,
Benue State University, Makurdi, Nigeria
Dr.Julie Ibu
Dr. Emmanuel Eru
Chief Inspector, Training and Counseling, National Youth Service Corps, Benue State, Nigeria
Senior Lecturer, Department of Physiology, College of Health Sciences,
Benue State University, Makurdi, Nigeria
Dr. Nndunno Akwaras
Linus Saluu
Professor, Human Anatomy, Department of Anatomy, College of Health Sciences
Benue State University, Makurdi, Nigeria
John Ibu
Professor, Department of Human Physiology College of Health Sciences,
Benue State University, Makurdi, Nigeria

\section{Abstract}

The effect of orally ingested substance on gastric acid secretion, have been subject to human investigation. This study was carried out to investigate the inhibitory effect of Moringa oleifera on gastric acid secretion. Fifteen (15) adult Wistar albino rats of both sexes weighing 300-450g were randomly allocated into three (3) groups of five (5) animals per group. Group 1 served as the control and was given normal saline without administrations of acid alcohol. Animals in group 2 were given acid alcohol $(0.25 \mathrm{ml}$ of $36 \% \mathrm{HCl}+75 \%$ ethanol $0.25 \mathrm{ml} / 100 \mathrm{~g}$ body weight). Animals in group 3 were given $50 \mathrm{mg} / 100 \mathrm{~g}$ body weight of Moringa oleifera 1 hour before acid alcohol was administered. The aqueous extract was administered through a gastric fistula and 10 minutes aliquot samples collected over 4 hours. Gastric acid secretion was measured by titrating the aliquots to a phenolphthalein end point. Result showed that Moringa oleifera significantly inhibits gastric acid secretion ( $p<$ 0.05), this effect was time dependent. Maximum inhibitory effect was seen after 4 hours of administration of Moringa oleifera but time of onset of action was within 2 hours.

Kevwords: Moringa oleifera, Acid alcohol, Gastric acid secretion

\section{Introduction}

Gastric juice is secreted by the glands in the mucous membrane of the stomach and its essential constituents are water, mucus, digestive enzymes such as pepsin and lipase, electrolytes and hydrochloric acid ( $\mathrm{HCl})$. The best-known component of gastric juice secreted in the stomach is $\mathrm{HCl}$ (gastric acid) and it is the secretory product of the parietal cell (Sung, 2016).

The effects of orally ingested substances on gastric function have been the subject of human investigation almost since the discovery of hydrochloric acid in gastric juice by Prout (1824). All foods are capable of stimulating gastric acid secretion through the distension of stomach but proteins are the major stimulants. Gastric acid secretion is a complex process that involves neuronal, hormonal, and endocrine pathways, all of which have one common target: the parietal cell. The parietal cell is responsible for secreting concentrated hydrochloric acid into the gastric lumen.

Agents that inhibit gastric acid secretion such as $\mathrm{H}_{2}$-receptor blockers (Cimetidine, Ranitidine etc.), proton pump inhibitors (omeprazole, rabeprazole etc.) are widely used to control increased acid secretion and acid related disorders. But however, adverse effects and relapse have been reported in the use of these agents The search for natural and available sources have led to the discovery several herbs used in the management several diseases including acid related 
disorders which are proved to be safe, clinically effective and relatively less expensive. One of these discovered herbs is Moringa oleifera.

Moringa Oleifera (Moringaceae) is a plant grown world-wide (Ming-Chih et al., 2011). Almost all parts of this plant -root, leaves, fruit, bark, seeds, and flowers are reported to have important medicinal values as cardiac and circulatory stimulants and to have antitumor, antipyretic, anti-inflammatory, antihypertensive, diuretic, cholesterol lowering, antidiabetic, antioxidant, antispasmodic, antibacterial, and antifungal activities (Mehta et at.,2011). Based on this numerous documented effect of moringa oleifera, this study was carried out to elucidate the effect of moringa olefera on gastric acid secretion for a period of 5hours.

\section{Materials and Method}

Fresh leaves of Moringa oleifera were collected from the natural habitat in Makurdi, Benue state, Nigeria. Sample of leaves collected were identified by a taxonomist from the Department of Botany in the Faculty of Science, Benue State University and were allocated a voucher number and deposited in the herbarium

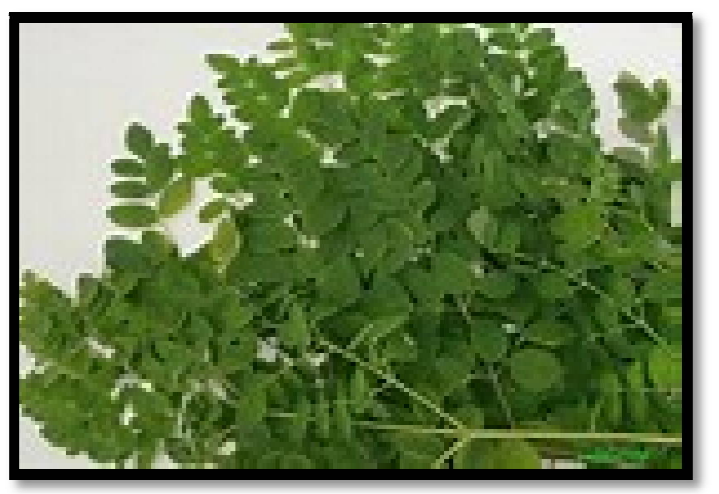

Figure 1: Leaves of Moringa Oleifera Used in This Study

\subsection{Preparation of Extract}

The leaves were sorted out to obtain only the fresh leaves and washed with distilled water without squeezing to remove debris and dust particles. They were shade dried for ten days and dried leaves pulverized with electric blender. A portion $(300 \mathrm{~g}$ ) of the powdered leaves were soaked in $1500 \mathrm{ml}$ of distilled water for $72 \mathrm{hours}$ with the solution thoroughly stirred twice daily according to the method of Onahinon et al (2018). The extract was filtered with WHATMAN no1 filter paper. The filtrate was dried using evaporator and then reconstituted before use

\subsection{Chemicals}

Urethane (ethylcarbam ate), $\mathrm{HCl}$ and Ethanol made by Sigma chemical Co. (Poole, UK). Marketed by Sigma Aldrich-USA. These were purchased from EMOLE chemical shop, old Otukpo road High Level Makurdi, Benue State Nigeria

\subsection{Animals}

Adult Wistar albino rats weighing 300-450g of either sex was purchased from the disease-free stock of the animal house of the College of Health Sciences, Benue State University, Makurdi and used for the study. They were maintained in normal and standard laboratory conditions of temperature $280 \mathrm{C}$ and relative humidity (with 12-hour light dark cycle) and adequate ventilation. The animals were fed with commercial diet (Vital Feed Nig. Ltd.) and water ad libitum. Food was withheld 12 hours before the experiments, but they had free access to water. Permission for the use of animals and animal house were obtained from the Animal Ethics Committee of Benue State University Makurdi, prior to experimentation

\subsection{Surgical Procedure and Induction of Ulcer}

After a 12 hour fast, each animal was anaesthetized with $25 \%$ Ethyl Carbonate (urethane) at a dose of $0.6 \mathrm{ml} / 100$ g body weight intraperitoneally. Tracheostomy was performed. A nasogastric tube was passed. A duodenostomy was performed and normal saline was used as gastric lavage to wash out the debris from the stomach until clear effluent was obtained. A duodenogastric canula was passed and ligated insitu for subsequent collection of gastric acid secretion Measurement of gastric acid secretion was done according to method of Gosh and Schild, (1958) and as modified by Ibu et at., (1986). Basal acid secretions was collected for the first 2 hours and titrated every 10 minutes for each hour. Moringa oleifera leaf aqueous extract was administered one hour before acid alcohol was given. The aliquots were collected every 10 mins for 120 mins (2hrs). Each aliquot was titrated to a phenolphthalein end point using $0.01 \mathrm{M} \mathrm{NaOH}$ and the acidoutput or concentration was calculated as described by Ibu et al., (1986)as follows:

Where Normality $=$ Molarity

$\mathrm{MA} \times \mathrm{VA}=\mathrm{MB} \times \mathrm{VB}$

$\mathrm{MA}=$

$(\mathrm{MB} \times \mathrm{VB}) \div \mathrm{VA}$.

Where, 
$\mathrm{MB}=$ Molarity of base known $(0.01 \mathrm{~N})=10 \mathrm{mMol}$

$\mathrm{VB}=$ Volume of base known (titrate of $\mathrm{NaOH}$ ) used

VA $=$ Volume of acid (effluent volume) $=10 \mathrm{ml}$

Substituting for $\mathrm{MB}$ and VA

$\mathrm{MA}=10 \times \mathrm{VB} \div 10$.

Therefore $\mathrm{MA}=\mathrm{VB}$

Acid output $/ 10$ minutes $=\mathrm{VB} \mathrm{mMol} / \mathrm{L} / 10$ mins

Acid output per hour = VB x $6 \mathrm{mMol} / \mathrm{L} /$ hour as stated by Ibuet al., (1986)

\subsubsection{Animal Grouping.}

The animals were randomly allocated into three (3) groups of 5 animals per group $(n=5)$ as follows:

- Control group: Administered normal saline orally 5 -10mls in 6 hours. (Ibu et al., 1986).

- Acid Alcohol group: (36\% HCL $0.25 \mathrm{ml}$ ) +75\% Ethanol 0.25ml/ 100g body weight (Sen et al., 2013).

- Moringa oleifera group: 50mg / 100 g body weights given $1 \mathrm{hr}$ before acid Alcohol (36\% HCL ( $0.25 \mathrm{ml})+75 \%$ Ethanol $(0.25 \mathrm{ml}) / 100 \mathrm{~g}$ body weights (Mahmood et al., 2009).

\subsection{Data Analysis}

Data obtained from the study was expressed as mean \pm SEM. The differences between the groups were analyzed by one-way analysis of variance (ANOVA), followed by Turkey's post Hoc test for multiple comparisons using SPSS statistical tool version 22 .

\section{Results}

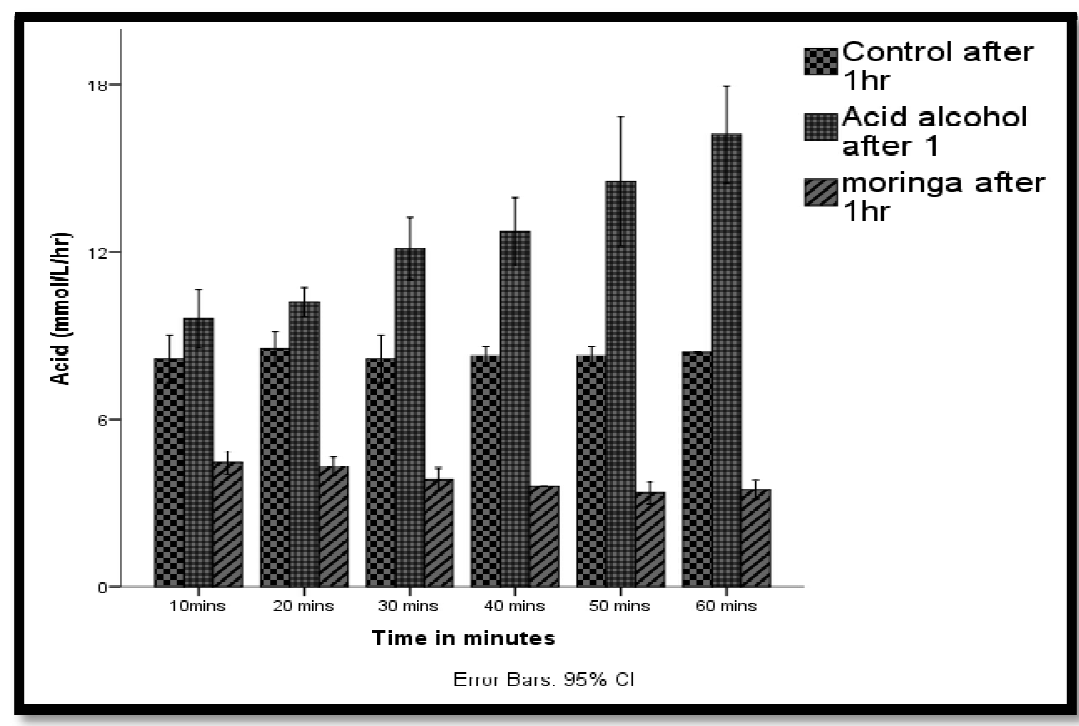

Figure 2: Gastric Acid Secretions in Control, Treated Rats with Acid Alcohol Alone and Moringa Alone 1hour after Administration of Acid Alcohol

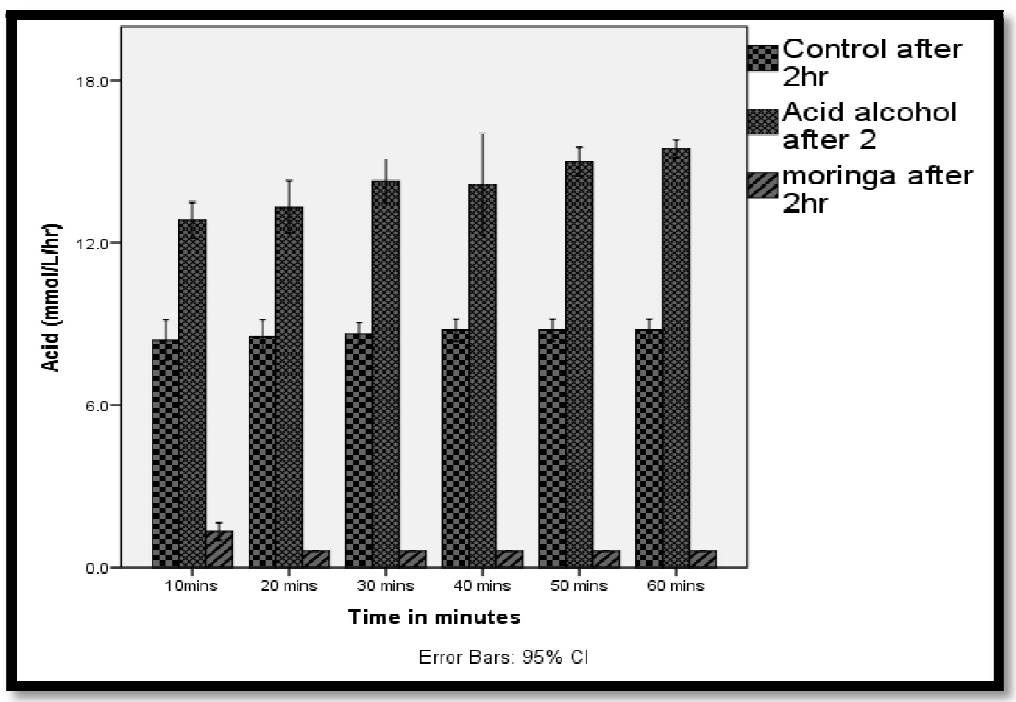

Figure 3: Gastric Acid Secretions in Control Rats, Rats Treated with Acid Alcohol Alone and Moringa Alone 2hours after Administration of Acid Alcohol 


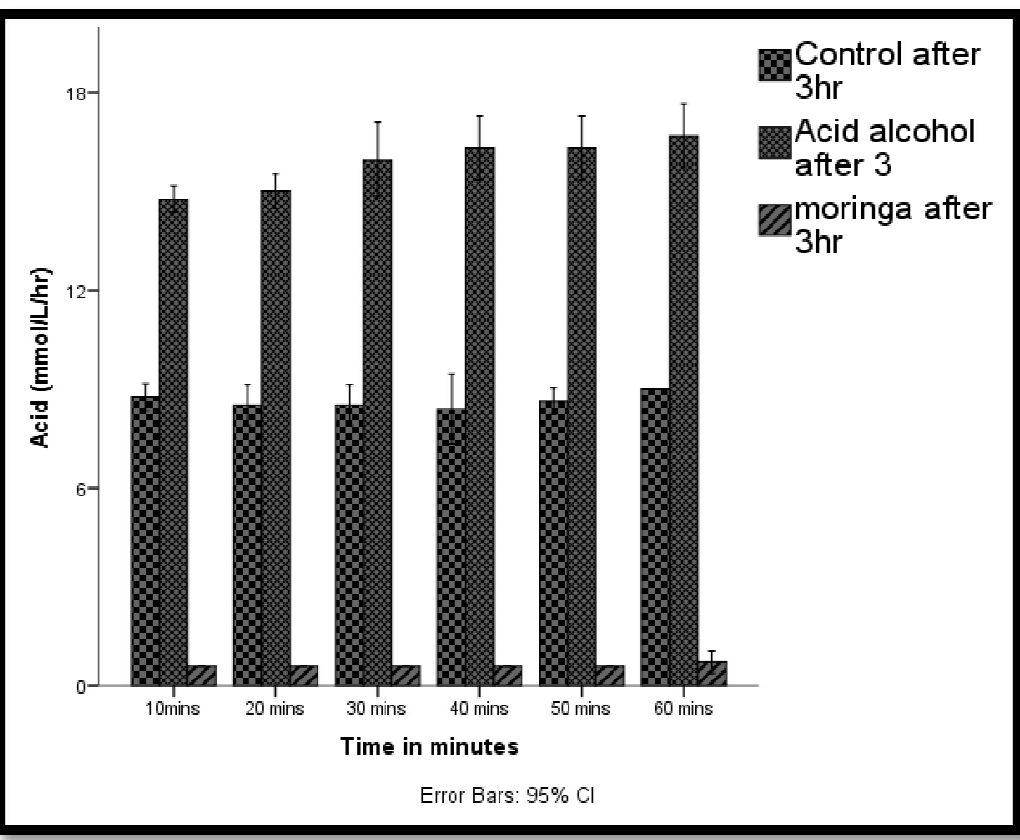

Figure 4: Gastric Acid Secretions in Control Rats, Treated Rats with Acid Alcohol Alone and Moringa Alone 3 Hours after Administration of Acid Alcohol

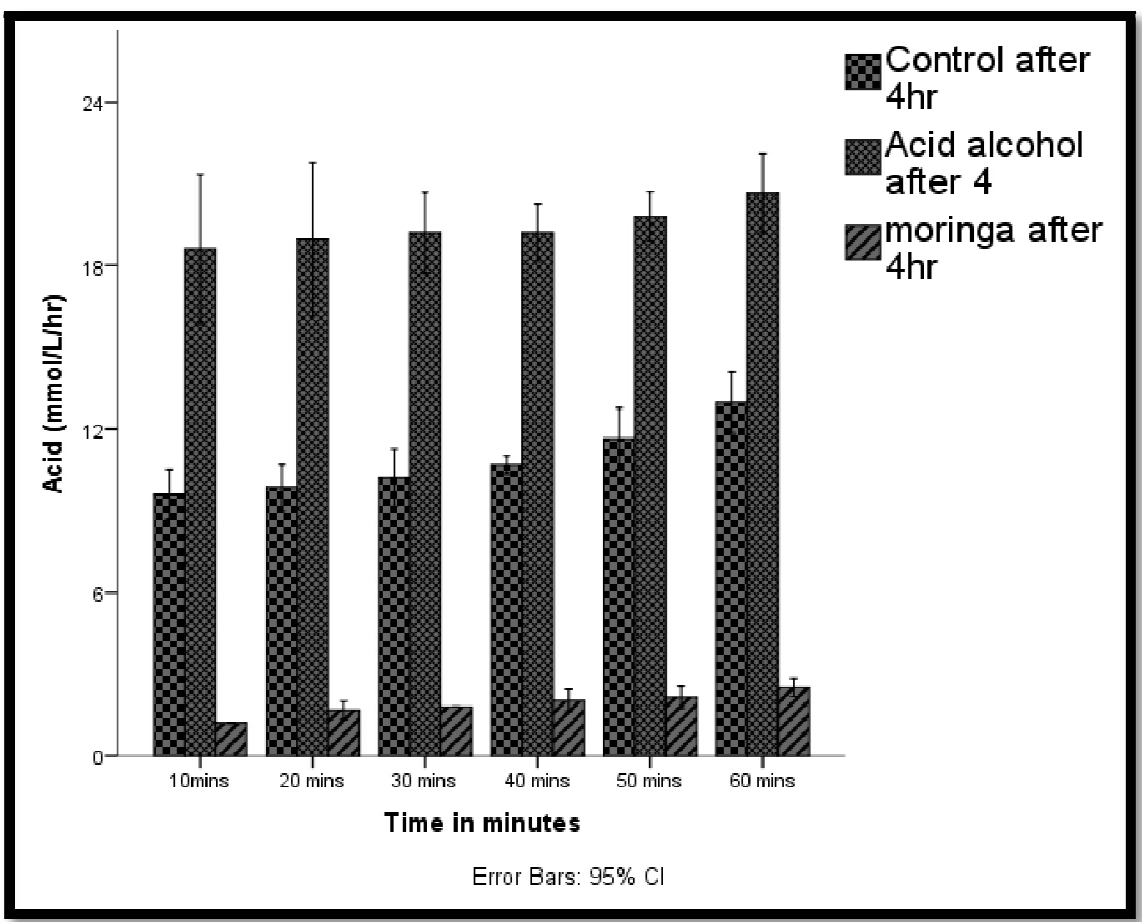

Figure 5: Gastric Acid Secretions in Control Rats, Treated Rats with Acid Alcohol Alone and Moringa Alone 4 Hours after Administration of Acid Alcohol 


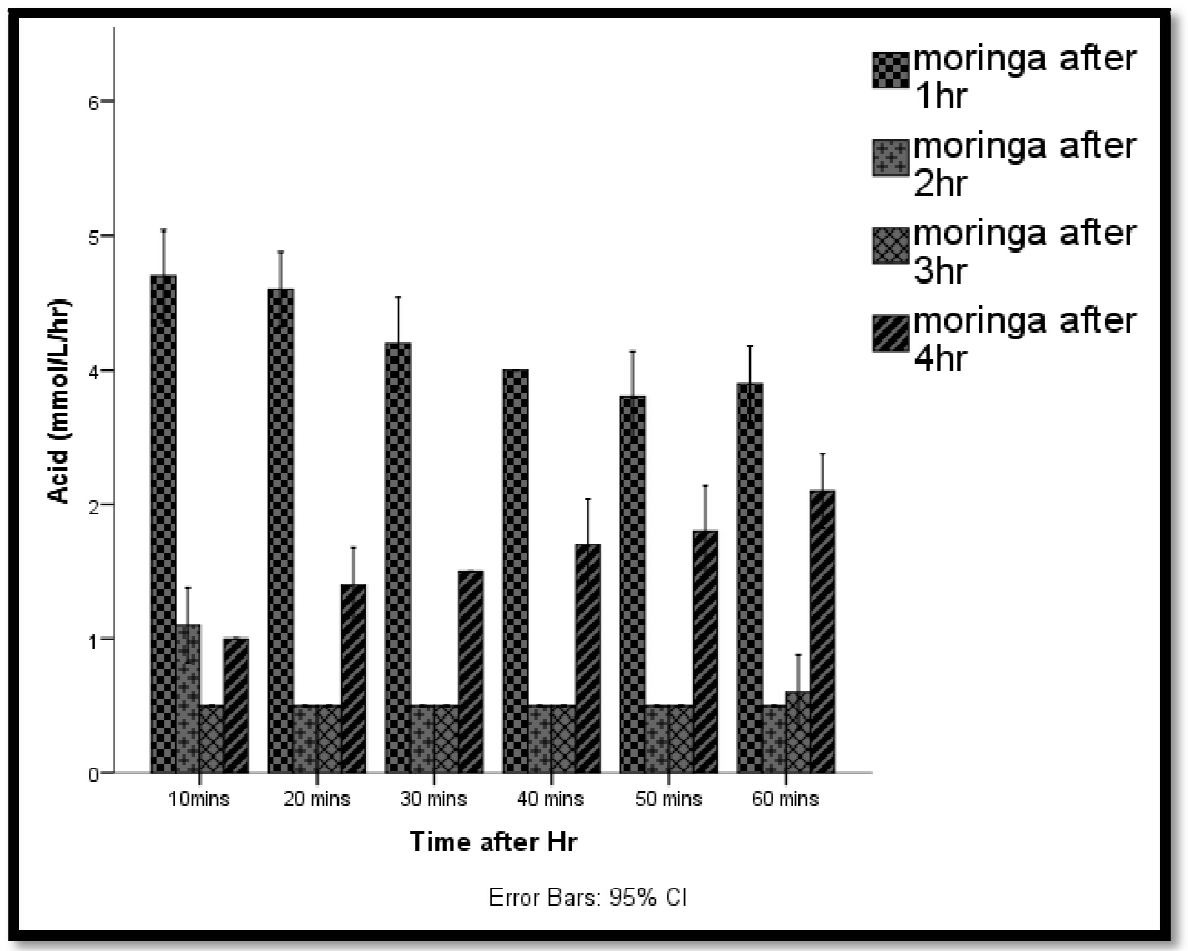

Figure 6: Gastric Acid Secretions in of Moringa Alone Treated Rats Taken1hour to 4 hours after Administration of Acid Alcohol, After the $4^{\text {th }}$ Hour, the Inhibitory Effect of Moringa Were Gradually Lost with Time

\section{Discussion}

The result from this study showed that acid alcohol significantly increased gastric acid secretion $(\mathrm{p}<0.01)$.this agrees with the work of Blandizziet al.,1999.The result from this study also showed that Moringa oleifera significantly reduce hypersecretory effect of acid alcohol on parietal cell. This agrees with other studies (Choudhary et al., 2013; Torreset al., 2013).

The mechanism by which Moringa oleifera reduces gastric acid secretion involves several pathways. Moringa oleifera have been demonstrated to trigger the release of Serotonin or 5-hydroxytryptamine (5-HT) (Siddartha and Debnath, 2007) - a monoamine neurotransmitter is found extensively in the gastrointestinal (GI) tract of animals (Schworer et al., 1987), from enterochromaffin (EC) cells (Penttila, 1966) of the gastric mucosa. 5-HT acting via 5-HT3 receptors have been reported to markedly reduce gastric acid secretion induced by oxotremorine, histamine or pentagastin (Yung-Chin et al.,2009). 5HT is a potent inhibitor of gastric acid secretion induced by cholinergic agonist oxotremorine and non -cholinergic agent such as histamine or pentagastrin (Yung-Chin et al.,2009). The action of Moringa oleifera on gastric acid secretion is thus achieved through the release of 5-HTwhich likely act through second massagersystem e.g. $\mathrm{Ca}^{2+}$,(Yung-Chin et al.,2009), which is involved in gastric acid secretion induced by acetylcholine, histamine or gastrin (Dufner et al., 2005)

Moringa oleifera also reduces gastric acid secretion through its anticholnergic mechanism. Moringa oleifera have been demonstrated to possess anticholinergic property (Ijioma et al.,2014). Stimulation of the parasympathetic (cholinergic) system results in the release of endogenous acetylcholine which acts on the gastrointestinal tract through muscarinic receptor (Gavril et al., 1992) to increase gastric acid secretion (Guyton and Hall, 1996)

The result from this study also showed that the maximum antisecretory activity of Moringa oleifera on the parietal cell was achieved after 200minutes (20minutes after 4 hours of administration od Moringa oleifera) 20 minutes after 2 hours of acid alcohol administration, although the time of onset of action was with 2hours after oral administration.

It was also observed that the effect of Moringa Oleifera on gastric acid secretion began to reduce after 6hours of administration as there was steady rise in gastric acid secretion as shown in figure 5.

These effects of Moringa oleifera is as a result of it several active constituents such as alkaloids, sterols, glycosides, flavonoids, and terpenoids (Mahajan et al., 2008) Also, its leaves are rich in benzyl isothiocyanate which has antiinflammatory activity (Lee et al., 2009).

\section{Conclusion}

Moringa oleifera significantly reduces gastric acid secretion with maximum antisecretory effect seen after 4hours and thereafter ware off. 


\section{References}

i. Blandizzi, C., Natale, G., Gherardi, G., Lazzeri, G., Marveggio, C., Colucci, R., ... and Del Tacca, M. (1999). Gastroprotective effects of pantoprazole against experimental mucosal damage. Fundamental \& clinical pharmacology, 14(2), 89-99.

ii. Choudhary, M. K., Bodakhe, S. H., \& Gupta, S. K. (2013). Assessment of the antiulcer potential of Moringa oleifera root-bark extract in rats. Journal of acupuncture and meridian studies, 6(4), 214-220.

iii. Dufner, M.M., Kirchhoff, P., Remy, C., Hafner, P., Muller, M.K., Cheng, S.X., Tang, L.Q., Hebert, S.C., Geibel, J.P. and Wagner, C.A. (2005). The calcium-sensing receptor acts as a modulator of gastric acid secretion in freshly isolated human gastric glands. Am. J.Physiol. Gastrointest. Liver Physiol. 289: G1084-G1090.

iv. Gavril, p., Ioana, V and Popovici, P. (1992). Role of gastrine and acetylcholine in gastric acid secretion mechanism. Annalele Universta Tii

v. Ghosh, M.N., and Schild H.O. (1958). Continuous recording of gastric acid secretion in Rat. BritJ. Pharm, 13: 54-61.

vi. $\quad$ Guyton, A.C., Hall, J.E. (1996). Textbook of Medical Physiology. W.B Saunders Company: Philadelphia. 771-778.

vii. Ibu J. O., Inyama, A.A., Ijije, C.T \& Ismael, D. (1986). The effect of the Cola Acuminata and Cola Nitida on Gastric Acid Secretion. Proc. West Afr. Soc. Gastroent. 1:3-4

viii. Ijioma, S., Nwosu, O., and Onyenegecha, C. (2014). Anticholinergic property ofethanol extract of Moringa oleifera leave: an in vivo and in vitro approach. Journal of Clinical and Experimental Research. 2(2):133-137

ix. Lee, Y.M., Seon, M.R., Cho, H.J., Kin, J., and Park, H.J. (2009). Benzyl isothiocyanate exhibits anti-inflammatory effects in murine macrophages and in mouse skin. J. Mol. Med. 87:1251-126.

x. Mahajan, S.G., Mehta, A.A and Mali, R.G. (2008). Protective effect of ethanolic extract of seeds of Moringa oleifera Lam. against inflammation associated with development of arthritis in rats. J. Immunotoxicol. 4(1): 39-47.

xi. Mahmood, A.A., Happah, M.A., Khaled, A.A., Suzita, M.N., and Samah I. (2009). Evaluation of the anti-ulcer activities of morus Alba extracts in experimentally -induced gastric ulcer in rats. Int. J. of medical sciences, ISSN; 0970-938, 0976-1683.

xii. Mehta J, Shukla A, Bukhariya V, Charde R. (2011). The magic remedy of Moringa oleifera: an overview. Int J Biomed Adv Res , 272-278

xiii. Ming-Chih, Shih., Cheng-Ming Chang., Sue-Ming Kang., Min-Lang Tsai (2011). Effect of different parts (leaf, stem and stalk) and seasons (summer and winter) on the chemical compositions and antioxidant activity of Moringa oleifera. Int J Mol Sci.; 12(9): 6077-6088

xiv. Onahinon, C., Eru, E., Ibu, J. Effect of Vernonia amygdalina Found in Alloxan Induced diabetes. International Journal of Research and Development 7(3) ,2018, 154-159

xv. Penttila, A. (1966). Histochemical reaction of the enterochromaffin cell and the 5-hydroxytryptamine content of the mammalian duodenum. Acta Physiogica Scandinavica, 69(1):281

xvi. Prout, W. (1824). On the nature of acid and saline matters usually existing in stomach of animals', Phil Trans,14: $45-49$

xvii. Schworer, H., Racke, K., and Kilbinger, H (1987). Spontaneous release Of endogenous 5-Hyroxytryptamine and 5Hydroxyindoacetic acid from isolated ileum of guinea pig. Neuroscience, 21:297

xviii. Sen S., Asokkumar K., Umamaheswari M., Sivashanmugam AT., Subhadradevi V. (2013). Antiulcerogenic Effect of Gallic Acid in Rats and its Effect on Oxidant and Antioxidant Parameters in Stomach Tissue. Indian Journal of Pharmaceutical Sciences, 75(2), 149-155

xix. Siddartha, D. and Dedjani, G. (2007). Role of Moringa oleifera on enterochromaffin cell count and serotonin content of experimental ulcer model. Indian Journal of Experimental Biology. 45:726-731

xx. Sung, J., Kim, N. and Kim J. (2016). 'Comparison of gastric microbiota between gastric juice and mucosa by next generation sequencing method', Journal ofCancer Prevention, 21(1):60-65.

xxi. Torres-Castillo, J. A., Sinagawa-García, S. R., Martínez-Ávila, G. C. G., López-Flores, A. B., Sánchez-González, E. I., Aguirre-Arzola, V. E., ... \& Gutiérrez-Díez, A. (2013). Moringa oleifera: phytochemical detection, antioxidants, enzymes and antifungal properties. International Journal of Experimental Botany, 82, 193-202.

xxii. Yung-Chin, L., Yih, H., Kai-Han, H and Li, H.T. (2009). Effect of serotonin on acid secretion in isolated rat stomach: the role of 5-HT 3 receptors. Chinese Journal of Physiology. 25(5):395-405 